\title{
Cardiotoxin III Inhibits Proliferation and Migration of Oral Cancer Cells through MAPK and MMP Signaling
}

\author{
Ching-Yu Yen, ${ }^{1,2}$ Shih-Shin Liang, ${ }^{3,4}$ Lo-Yi Han, ${ }^{4}$ Han-Lin Chou, ${ }^{4}$ Chon-Kit Chou, \\ Shinne-Ren Lin, ${ }^{5}$ and Chien-Chih $\mathrm{Chiu}^{4}$ \\ ${ }^{1}$ Department of Oral and Maxillofacial Surgery, Chi-Mei Medical Center, Tainan 710, Taiwan \\ ${ }^{2}$ School of Dentistry, Taipei Medical University, Taipei 110, Taiwan \\ ${ }^{3}$ Cancer Center, Kaohsiung Medical University Hospital, Kaohsiung Medical University, Kaohsiung 807, Taiwan \\ ${ }^{4}$ Department of Biotechnology, Kaohsiung Medical University, Kaohsiung 807, Taiwan \\ ${ }^{5}$ Department of Medicinal and Applied Chemistry, Kaohsiung Medical University, Kaohsiung 807, Taiwan
}

Correspondence should be addressed to Shinne-Ren Lin; shreli@kmu.edu.tw and Chien-Chih Chiu; cchiu@kmu.edu.tw

Received 18 February 2013; Accepted 12 March 2013

Academic Editors: H.-W. Chang, L.-Y. Chuang, S. Guleria, and S. Yasmin

Copyright (C) 2013 Ching-Yu Yen et al. This is an open access article distributed under the Creative Commons Attribution License, which permits unrestricted use, distribution, and reproduction in any medium, provided the original work is properly cited.

Cardiotoxin III (CTXIII), isolated from the snake venom of Formosan cobra Naja naja atra, has previously been found to induce apoptosis in many types of cancer. Early metastasis is typical for the progression of oral cancer. To modulate the cell migration behavior of oral cancer is one of the oral cancer therapies. In this study, the possible modulating effect of CTXIII on oral cancer migration is addressed. In the example of oral squamous carcinoma Ca9-22 cells, the cell viability was decreased by CTXIII treatment in a dose-responsive manner. In wound-healing assay, the cell migration of Ca9-22 cells was attenuated by CTXIII in a dose- and time-responsive manner. After CTXIII treatment, the MMP-2 and MMP-9 protein expressions were downregulated, and the phosphorylation of JNK and p38-MAPK was increased independent of ERK phosphorylation. In conclusion, CTXIII has antiproliferative and -migrating effects on oral cancer cells involving the p38-MAPK and MMP-2/-9 pathways.

\section{Introduction}

Oral squamous cell carcinoma (OSCC), the sixth most common form of cancer worldwide $[1,2]$, especially occurs in India, Taiwan, and Southeast Asia [3, 4]. Although many antioral cancer drugs were reported [5-9], the drug discovery against oral cancer remains a challenge.

Cardiotoxin III (CTXIII), composed of 60 basic amino acid residues, is isolated from the snake venom of Formosan cobra Naja naja atra. Although some anticancer drugs such as doxorubicin, anthracyclines, and trastuzumab have the wellknown cardiotoxicity [10, 11], CTXIII was found to exhibit a variety of bioactivities with anticancer potential. For example, we previously found that CTXIII inhibits the cellular proliferation and induces apoptosis of various cancer cells, including breast cancer [12], leukemia cells [13], colorectal cancer [14], and oral cancer $[15,16]$.
The metastasis plays an important role in oral carcinogenesis [17]. However, little is known about the antimigration effect of CTXIII on oral cancer cells. In this study, we evaluated the role of CTXIII on cellular proliferation and migration of oral cancer cells Ca9-22. The role of mitogenactivated protein kinase (MAPK) family in CTXIII-induced antimigration in oral cancer cells was also investigated.

\section{Methods}

2.1. CTXIII Isolation. The isolation procedure of CTXIII was described previously [18]. Briefly, CTX III was purified from the venom of Naja naja atra, the Formosan cobrausing a chromatography on Sephadex G-50 and SP-Sephadex C-25. CTX III was dissolved in phosphate buffered saline (PBS) and filter sterilized through $0.2 \mu \mathrm{m}$ pore-size membrane filter (Millipore Corp, Bedford, MA, USA). 
2.2. Cell Cultures. Human gingival carcinoma Ca9-22 cells [5] were cultured in DMEM-F12 medium (Gibco, Grand Island, NY). Cells were supplemented with $10 \%$ fetal bovine serum (FBS), $100 \mathrm{U} / \mathrm{mL}$ penicillin, $100 \mu \mathrm{g} / \mathrm{mL}$ streptomycin, $0.03 \%$ glutamine, and $1 \mathrm{mM}$ sodium pyruvate. Cells were kept at $37^{\circ} \mathrm{C}$ in a humidified atmosphere containing $5 \% \mathrm{CO}_{2}$.

2.3. Growth Inhibition Test. The growth inhibition was determined by trypan blue dye exclusion assay combined with the Countess automated cell counter (Invitrogen, Carlsbad, CA, USA) as described previously $[19,20]$. In brief, $1 \times 10^{5}$ Ca922 cells were seeded on a 12 -well plate. Cells were treated with PBS as vehicle or indicated concentrations for $24 \mathrm{~h}$, respectively. After incubation, cells harvested and exposed to $0.2 \%$ Trypan blue were counted.

2.4. Wound-Healing Assay. Cell migration was examined by wound-healing assay as described [21]. Briefly, a total of $3 \times 10^{5}$ Ca9-22 cells were seeded onto 12 -well plates and then grown to complete confluence. A $200 \mu \mathrm{L}$ plastic pipette tip was used to scratch the culture monolayer and create a clean $1 \mathrm{~mm}$ wide wound area. Cells were treated with PBS (as vehicle control) or indicated concentrations of CTXIII (from 1,3 , and $5 \mu \mathrm{g} / \mathrm{mL}$ ). After incubation for $8 \mathrm{~h}$, wound gaps were photographed at each time interval. The wound areas were then analyzed and calculated using the online software Wimasis (http://www.wimasis.com/; Wimasis GmbH, Munich, Germany).

2.5. Western Blotting. Western blot assay was described previously [22]. Briefly, cells were harvested and lysed. Lysates were centrifuged, and the protein concentration was determined. A total of $40 \mu \mathrm{g}$ protein lysates were resolved by $10 \%$ SDS-polyacrylamide gel electrophoresis (SDS-PAGE) and then electrotransferred to $0.22 \mu \mathrm{m}$ pore-size nitrocellulose membranes (Pall Life Sciences, Ann Arbor, MI). Membranes were blocked with 5\% nonfat milk. Afterwards, the membranes were incubated with primary antibodies against MMP-2 (AnaSpec, no.29575), MMP-9 (AnaSpec, no.53678), phospho-JNK (Thr183/Tyr185, Upstate, no.07-175), phosphop38 (Tyr182, Santa Cruz Biotech., sc-7973), phospho-ERK (Tyr204, Santa Cruz Biotech., sc-7976), and $\beta$-actin (Santa Cruz, sc-7963), their corresponding secondary antibodies, respectively. The signals were detected using a chemiluminescence detection kit ECL (Amersham Piscataway, NJ, USA).

2.6. Statistical Analysis. All data are presented as the means \pm SD. All data were analyzed by Student's $t$-test.

\section{Results}

3.1. The Effect of CTXIII on Cellular Growth of Ca9-22 Cells. To examine the effect of CTXIII on cell growth, Ca9-22 cells were treated with PBS as vehicle control or indicated concentrations of CTXIII $(1,3$, and $5 \mu \mathrm{g} / \mathrm{mL})$ for $24 \mathrm{~h}$, respectively. As shown in Figure 1, the cell viability was assessed by trypan blue exclusion assay, and CTXIII exerted

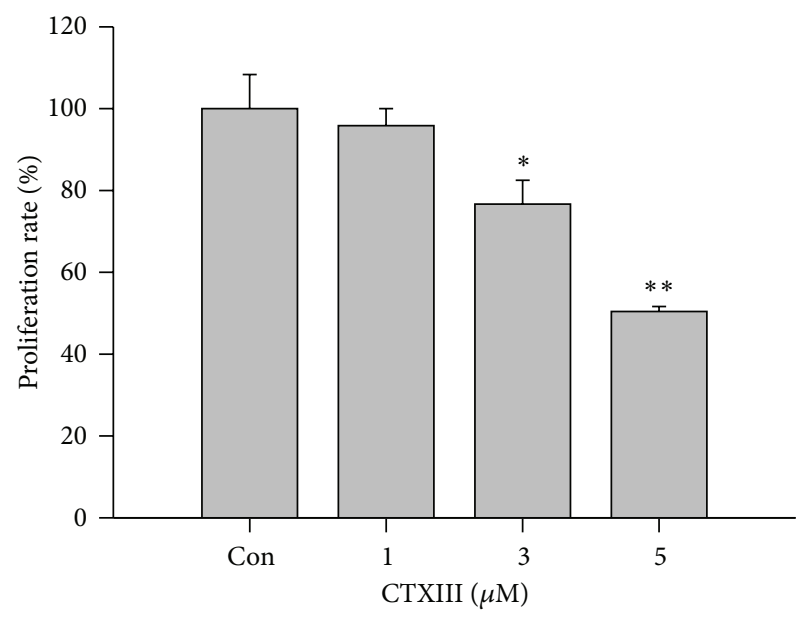

FIGURE 1: Inhibitory effect of CTXIII on proliferation of Ca9-22 cells. Cells were incubated with indicated concentrations of CTXIII (from $0,1,3$, and $5 \mu \mathrm{g} / \mathrm{mL}$ ) for $24 \mathrm{~h}$. The proliferation inhibition was determined by trypan blue exclusion assay. Data, means \pm SD $(n=3) .{ }^{*} P<0.05$ and ${ }^{* *} P<0.001$ for control versus CTXIIItreated, respectively.

a moderate cytotoxic effect on cell proliferation in a doseresponsive manner.

3.2. CTXIII Attenuates the Migration of Ca9-22 Oral Cancer Cells. Figure 2 showed that the migration of Ca9-22 oral cancer cells was significantly inhibited by CTXIII at concentrations of 2,3 , and $5 \mu \mathrm{M}$. Additionally, the cell motility of CTXIII-treated Ca9-22 cells was inhibited in a doseresponsive and time-dependent manner.

3.3. Assessment of the MMP-2 and MMP-9 Expressions. To examine whether CTXIII-induced anticellular migration involves the regulation of the expression of MMPs, Ca9-22 cells treated with indicated concentrations of CTXIII (vehicle control, 3 and $5 \mu \mathrm{g} / \mathrm{mL}$ ) were subjected to the Western blotting assay. As shown in Figure 3, both MMP-2 and MMP9 expressions were downregulated in CTXIII-treated Ca9-22 cells.

3.4. Assessment of the Mitogen-Activated Protein Kinase (MAPK) Signaling. To examine whether p38-MAPK involves CTXIII-induced migration-inhibitory effect, Ca9-22 cells treated at concentrations of CTXIII (vehicle control, 3 and $5 \mu \mathrm{g} / \mathrm{mL}$ ) were subjected to the Western blotting assay. In CTXIII-treated Ca9-22 cells (Figure 4), the phosphorylation of JNK and p38-MAPK was increase, but the phosphorylation of ERK was not affected.

\section{Discussion}

In this study, the antiproliferation effect was found in CTXIII-treated oral cancer Ca9-22 cells. The inactivation of epidermal growth factor receptor (EGFR) and downstream pathways [15] and Src kinase were found to involve apoptosis 


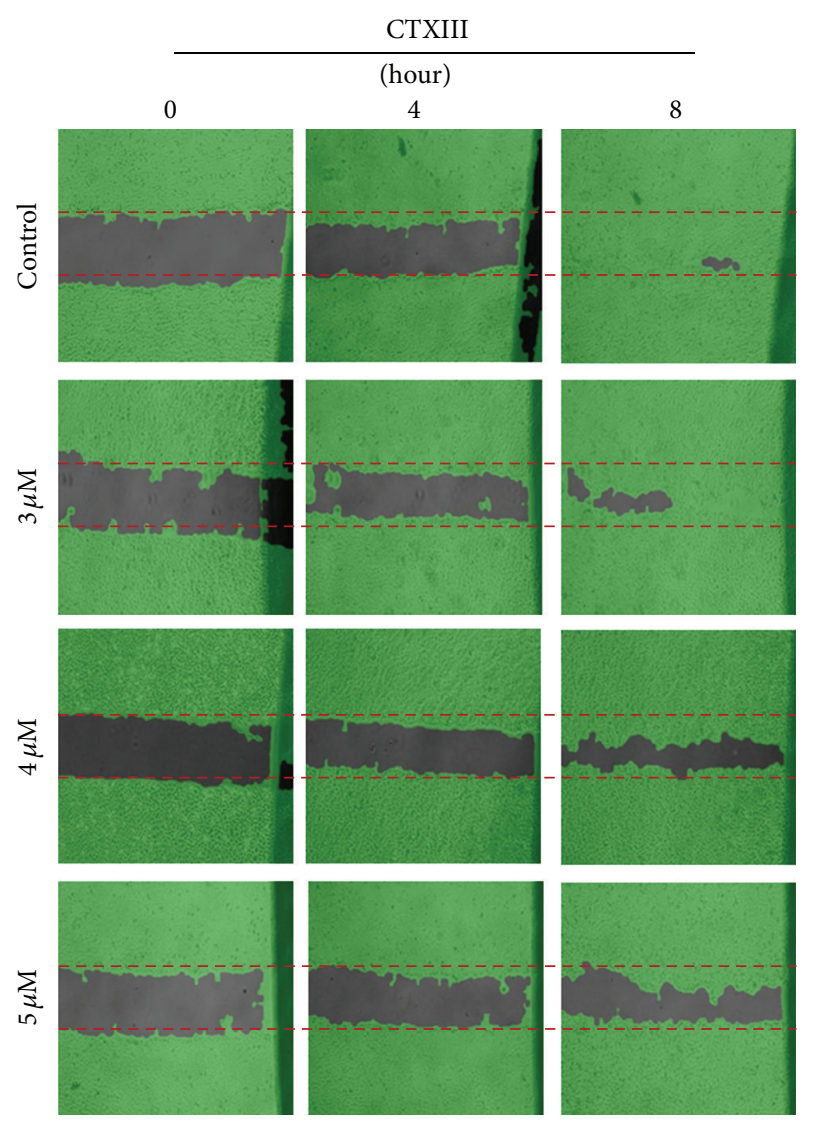

(a)

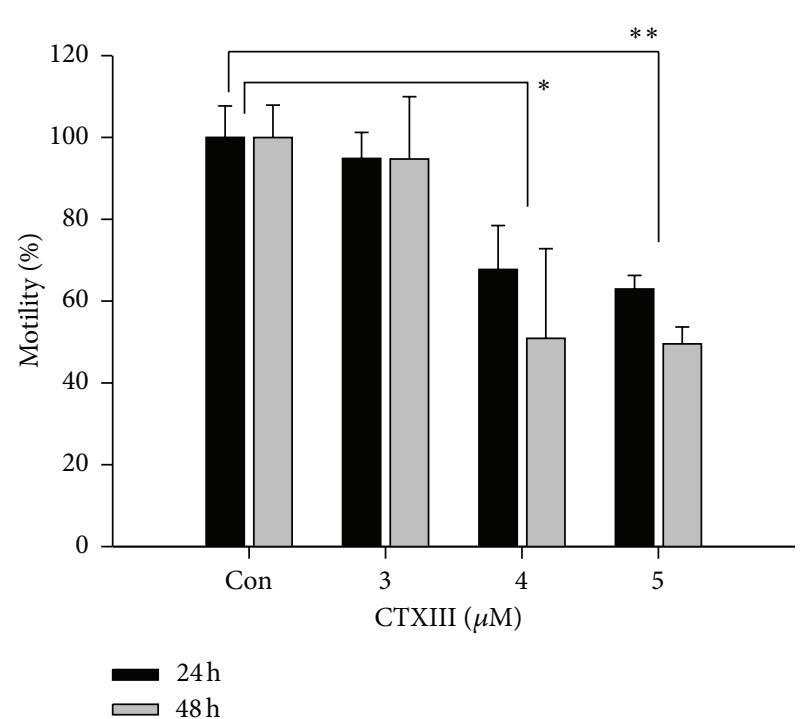

(b)

FIGURE 2: CTXIII inhibits cellular migration of Ca9-22 oral cancer cells. (a) $5 \times 10^{5}$ cells were seeded onto a 12-well plate, and cells were scraped to create a clean $1 \mathrm{~mm}$ wide wound area. Cells then were treated with the indicated doses of vehicle control, 3, 4, and $5 \mu \mathrm{g} / \mathrm{mL}$ of CTXIII for 8 hours. The wound areas were then analyzed and calculated using an online image analysis software Wimasis. (b) The quantitative results. Data, means $\pm \mathrm{SD}(n=3) .{ }^{*} P<0.05$ and ${ }^{* *} P<0.001$ for control versus CTXIII treated, respectively.

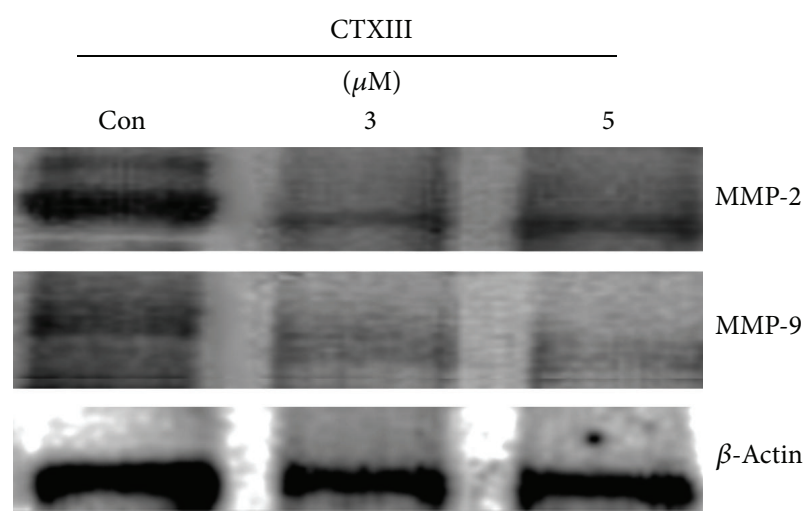

Figure 3: The regulation of MMP-2 and -9 expressions by CTXIII. Ca9-22 cells were treated with vehicle control, 3 and $5 \mu \mathrm{g} / \mathrm{mL}$ of CTXIII for $24 \mathrm{~h}$, respectively. Two major prometastasis associated extracellular matrix metalloproteinases MMP-2 and MMP-9 were examined using the Western blot assay. $\beta$-Actin was used as an internal control. Each representative blot was performed in at least triplication.

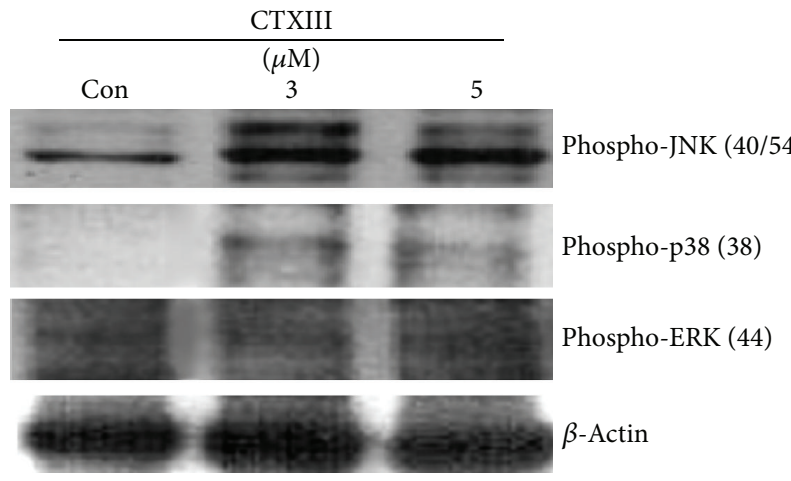

FIGURE 4: The regulation of MAPK signaling by CTXIII. Ca9-22 cells were treated with vehicle control, 3 and $5 \mu \mathrm{g} / \mathrm{mL}$ of CTXIII for $24 \mathrm{~h}$, respectively. The phosphorylation levels of three major MAPK members JNK, p38, and ERK were examined using the Western blot assay. $\beta$-Actin was used as an internal control. Each representative blot was performed in at least triplication.

and cell cycle arrest of Ca9-22 cells after CTXIII treatment [16].

For other types of cancer cells, the antiproliferation and apoptosis-inducible effects of CTXIII have been reported $[12-16,23,24]$. The detailed mechanism of CTXIII-induced apoptosis have well demonstrated, such as mitochondrial alteration, reactive oxygen species generation of neuroblastoma SK-N-SH cells [23], NF- $\kappa$ B inactivation in breast MCF7 cancer cells [12], and downregulation of the JAK2/PI3K signaling in breast MDA-MB-231 cancer cells [24].

In addition to the antiproliferation and apoptosisinducible effects, we found that CTXIII can inhibit the migration of oral cancer cells. Early metastasis is a critical step for oral carcinogenesis and the overexpression of MMP9, and extracellular matrix metalloproteinase leads to a poor prognosis of oral cancer [25]. Therefore, we found that downregulation of MMP-9 in oral cancer cells by CTXIII 


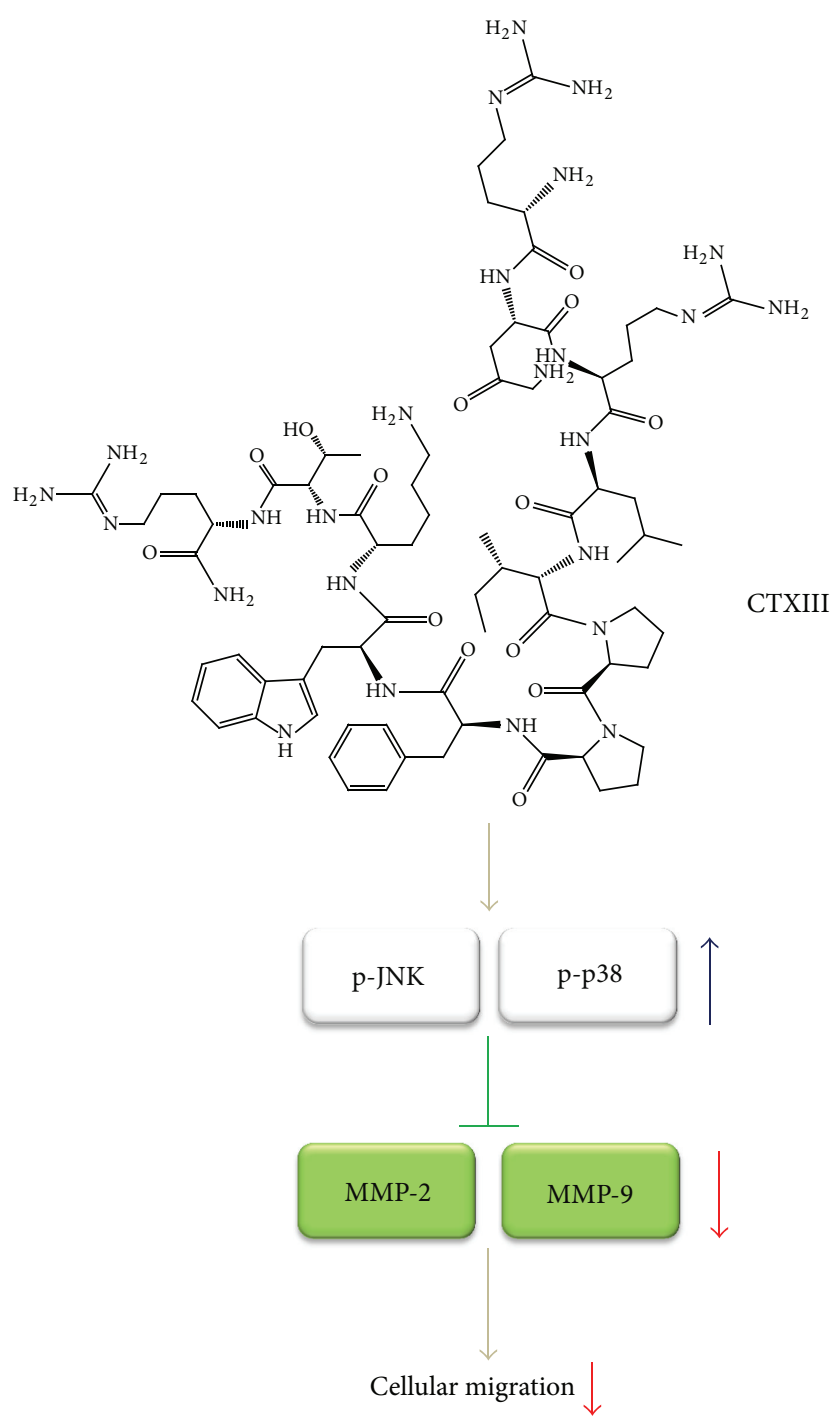

FIGURE 5: Proposed schematic mechanism of CTXIII-induced antimigration in human oral cancer cells. In current study, CTXIII exerts the antimigration potential against $\mathrm{Ca} 9-22$ cells in a doseresponsive manner. CTXIII causes the activation of MAPK member JNK and p38 without affecting ERK signaling. This may downregulate the expression levels of MMP-2 and MMP-9, the two major migration-associated extracellular matrix proteinases. Finally, the downregulated MMP-2 and MMP-9 expressions result in attenuating the migration potential of $\mathrm{Ca} 9-22$ cells.

treatment was helpful to therapeutic effect of oral cancer. Because MMPs are highly expressed in invasive tumors, it may play a vital role in tumor invasion and metastasis [26]. For example, the levels of MMP-2 and MMP-9 proteins were related to invasion of oral cancer [27]. Several drugs such as goniothalamin [21] and $17 \beta$-estradiol [28] were reported to inhibit the migration of lung and colon cancer cells by attenuating MMP-2 and MMP-9 activities, respectively. Consistently, the CTXIII mediated MMP2/9 to inhibit the migration of oral cancer cells in current study.

p38-MAPK can regulate invasion by modulation of MMP-2/-9 mRNA level and zymographic activity in bladder cancer model [29]. p38-MAPK also modulated the inhibition of migration in $17 \beta$-estradiol-treated human colon cancer cells by inhibition of MMP-2/-9 expression [28]. Similar to the current study, CTXIII-induced inhibition of migration downregulated the p38-MAPK phosphorylation and MMP2/9 protein expression. Consistent with these findings, both MMP-2/-9 and invasive activities were enhanced by exogenous expression of wild-type MAPK-activated protein kinase 2 and inhibited by p38-MAPK inhibitor [29].

Although the p38-MAPK and MMP-2/-9 were mediated in CTXIII-induced inhibition of migration in oral cancer cells, the phosphorylation of ERK was not involved in current study. Similarly, TGF- $\beta$-induced overexpression of MMP- 2 and MMP-9 was mediated by p38 MAPK but not by ERK signaling in breast cancer cells [30]. Other mechanisms also reported the antimetastatic potential of CTXIII in breast cancer, such as EGFR signaling [18] and PI3K/Akt and p38 MAPK signaling [31].

\section{Conclusions}

This study demonstrates the roles of p38-MAPK and MMP2/-9 pathways involved in the inhibition effect of proliferation and migration under CTXIII treatment in human oral cancer cells (Figure 5), and it may provide a potential oral cancer therapy.

\section{Conflict of Interests}

The authors declare no conflict of interests in the study.

\section{Acknowledgments}

This study was financially supported by Grants NSC1012313-B-037-001 and NSC101-2320-B-037-046-MY3 from the National Science Council, Taiwan; by Grant DOH102-TDC-111-002 from the Taiwan Department of Health; by Grant 101-CM-KMU-06 from ChiMei-KMU Joint Research Project; by Grant NSYSUKMU 102-28 from the NSYSU-KMU Joint Research Project. The authors also thank Professor Yao Fong at Chest Surgery, Chi-Mei Foundation Medical Center, Taiwan, for his help in the statistical and reagent supporting.

\section{References}

[1] D. M. Parkin, E. Laara, and C. S. Muir, "Estimates of the worldwide frequency of sixteen major cancers in 1980," International Journal of Cancer, vol. 41, no. 2, pp. 184-197, 1988.

[2] R. Mishra, "Biomarkers of oral premalignant epithelial lesions for clinical application," Oral Oncology, vol. 48, no. 7, pp. 578584, 2012.

[3] M. A. Moore, Y. Ariyaratne, F. Badar et al., "Cancer epidemiology in South Asia-past, present and future," Asian Pacific Journal of Cancer Prevention, vol. 11, supplement 2, pp. 49-66, 2010.

[4] Y. C. Ko, Y.-L. Huang, C.-H. Lee, M.-J. Chen, L.-M. Lin, and C.-C. Tsai, "Betel quid chewing, cigarette smoking and alcohol consumption related to oral cancer in Taiwan," Journal of Oral Pathology and Medicine, vol. 24, no. 10, pp. 450-453, 1995. 
[5] C. Y. Yen, C. C. Chiu, R. W. Haung et al., "Antiproliferative effects of goniothalamin on Ca9-22 oral cancer cells through apoptosis, DNA damage and ROS induction," Mutation Research, vol. 747, no. 2, pp. 253-258, 2012.

[6] C. C. Yeh, J. I. Yang, J. C. Lee et al., "Anti-proliferative effect of methanolic extract of Gracilaria tenuistipitata on oral cancer cells involves apoptosis, DNA damage, and oxidative stress," BMC Complementary and Alternative Medicine, vol. 12, no. 1, article 142, 2012.

[7] C. C. Yeh, C. N. Tseng, J. I. Yang et al., "Antiproliferation and induction of apoptosis in Ca9-22 oral cancer cells by ethanolic extract of Gracilaria tenuistipitata," Molecules, vol. 17, no. 9, pp. 10916-10927, 2012.

[8] J. W. Kang, J. H. Kim, K. Song, S. H. Kim, J. H. Yoon, and K. S. Kim, "Kaempferol and quercetin, components of Ginkgo biloba extract (EGb 761), induce caspase-3-dependent apoptosis in oral cavity cancer cells," Phytotherapy Research, vol. 24, supplement 1, pp. S77-S82, 2010.

[9] C. H. Liang, G. H. Wang, C. C. Liaw et al., "Extracts from Cladiella australis, Clavularia viridis and Klyxum simplex (soft corals) are capable of inhibiting the growth of human oral squamous cell carcinoma cells," Marine Drugs, vol. 6, no. 4, pp. 595-606, 2008.

[10] S. Geiger, V. Lange, P. Suhl, V. Heinemann, and H. J. Stemmler, "Anticancer therapy induced cardiotoxicity: review of the literature," Anti-Cancer Drugs, vol. 21, no. 6, pp. 578-590, 2010.

[11] P. K. Singal and N. Iliskovic, "Doxorubicin-induced cardiomyopathy," The New England Journal of Medicine, vol. 339, no. 13, pp. 900-905, 1998.

[12] C. C. Chiu, K. L. Lin, C. M. Chien, L. S. Chang, and S. R. Lin, "Effects of cardiotoxin III on NF- $\kappa$ B function, proliferation, and apoptosis in human breast MCF-7 cancer cells," Oncology Research, vol. 17, no. 7, pp. 311-321, 2009.

[13] S. H. Yang, C. M. Chien, L. S. Chang, and S. R. Lin, "Involvement of c-jun N-terminal kinase in G2/M arrest and caspasemediated apoptosis induced by cardiotoxin III (Naja naja atra) in K562 leukemia cells," Toxicon, vol. 49, no. 7, pp. 966-974, 2007.

[14] C. H. Tsai, S. H. Yang, C. M. Chien et al., "Mechanisms of cardiotoxin III-induced apoptosis in human colorectal cancer Colo205 Cells," Clinical and Experimental Pharmacology and Physiology, vol. 33, no. 3, pp. 177-182, 2006.

[15] C. M. Chien, K. L. Lin, J. C. Su, L. S. Chang, and S. R. Lin, "Inactivation of epidermal growth factor receptor and downstream pathways in oral squamous cell carcinoma Ca9-22 cells by cardiotoxin III from Naja naja atra," Journal of Natural Products, vol. 72, no. 10, pp. 1735-1740, 2009.

[16] C. M. Chien, S. Y. Chang, K. L. Lin, C. C. Chiu, L. S. Chang, and S. R. Lin, "Taiwan cobra cardiotoxin III inhibits Src kinase leading to apoptosis and cell cycle arrest of oral squamous cell carcinoma Ca9-22 cells," Toxicon, vol. 56, no. 4, pp. 508-520, 2010.

[17] J. Noguti, C. F. De Moura, G. P. De Jesus et al., "Metastasis from oral cancer: an overview," Cancer Genomics Proteomics, vol. 9, no. 5, pp. 329-335, 2012.

[18] P. C. Tsai, C. Y. Hsieh, C. C. Chiu, C. K. Wang, L. S. Chang, and S. R. Lin, "Cardiotoxin III suppresses MDA-MB-231 cell metastasis through the inhibition of EGF/EGFR-mediated signaling pathway," Toxicon, vol. 60, no. 5, pp. 734-743, 2012.

[19] C. Y. Yen, C. C. Chiu, F. R. Chang et al., “ $4 \beta$-hydroxywithanolide E from Physalis peruviana (golden berry) inhibits growth of human lung cancer cells through DNA damage, apoptosis and G2/M arrest," BMC Cancer, vol. 10, article 46, 2010.

[20] C. C. Chiu, H. W. Chang, D. W. Chuang et al., "Fern plantderived protoapigenone leads to DNA damage, apoptosis, and $\mathrm{G}_{2} / \mathrm{M}$ arrest in lung cancer cell line H1299," DNA and Cell Biology, vol. 28, no. 10, pp. 501-506, 2009.

[21] C. C. Chiu, P. L. Liu, K. J. Huang et al., "Goniothalamin inhibits growth of human lung cancer cells through DNA damage, apoptosis, and reduced migration ability," Journal of Agricultural and Food Chemistry, vol. 59, no. 8, pp. 4288-4293, 2011.

[22] C. C. Chiu, J. Y. F. Chen, K. L. Lin et al., "P38 MAPK and NF$\kappa \mathrm{B}$ pathways are involved in naphtho[1,2-b] furan-4,5-dione induced anti-proliferation and apoptosis of human hepatoma cells," Cancer Letters, vol. 295, no. 1, pp. 92-99, 2010.

[23] K. C. Chen, S. R. Lin, and L. S. Chang, "Involvement of mitochondrial alteration and reactive oxygen species generation in Taiwan cobra cardiotoxin-induced apoptotic death of human neuroblastoma SK-N-SH cells," Toxicon, vol. 52, no. 2, pp. 361368, 2008.

[24] K. L. Lin, J. C. Su, C. M. Chien, P. W. Chuang, L. S. Chang, and S. R. Lin, "Down-regulation of the JAK2/PI3K-mediated signaling activation is involved in Taiwan cobra cardiotoxin III-induced apoptosis of human breast MDA-MB-231 cancer cells," Toxicon, vol. 55, no. 7, pp. 1263-1273, 2010.

[25] S. T. Vilen, T. Salo, T. Sorsa, and P. Nyberg, "Fluctuating roles of matrix metalloproteinase- 9 in oral squamous cell carcinoma," The Scientific World Journal, vol. 2013, Article ID 920595, 11 pages, 2013.

[26] J. C. de Vicente, M. F. Fresno, L. Villalain, J. A. Vega, and G. Hernández Vallejo, "Expression and clinical significance of matrix metalloproteinase- 2 and matrix metalloproteinase- 9 in oral squamous cell carcinoma," Oral Oncology, vol. 41, no. 3, pp. 283-293, 2005.

[27] J. Esparza, C. Vilardell, J. Calvo et al., "Fibronectin upregulates gelatinase B (MMP-9) and induces coordinated expression of gelatinase A (MMP-2) and its activator MT1-MMP (MMP-14) by human T lymphocyte cell lines. A process repressed through RAS/MAP kinase signaling pathways," Blood, vol. 94, no. 8, pp. 2754-2766, 1999.

[28] H. H. Hsu, C. J. Liu, C. Y. Shen et al., "p38alpha MAPK mediates 17beta-estradiol inhibition of MMP-2 and -9 expression and cell migration in human lovo colon cancer cells," Journal of Cellular Physiology, vol. 227, no. 11, pp. 3648-3660, 2012.

[29] B. Kumar, S. Koul, J. Petersen et al., "p38 Mitogen-activated protein kinase-driven MAPKAPK2 regulates invasion of bladder cancer by modulation of MMP-2 and MMP-9 activity," Cancer Research, vol. 70, no. 2, pp. 832-841, 2010.

[30] E. S. Kim, M. S. Kim, and A. Moon, "TGF-beta-induced upregulation of MMP-2 and MMP-9 depends on p38 MAPK, but not ERK signaling in MCF10A human breast epithelial cells," International Journal of Oncology, vol. 25, no. 5, pp. 1375$1382,2004$.

[31] K. L. Lin, C. M. Chien, C. Y. Hsieh, P. C. Tsai, L. S. Chang, and S. R. Lin, "Antimetastatic potential of cardiotoxin III involves inactivation of PI3K/Akt and p38 MAPK signaling pathways in human breast cancer MDA-MB-231 cells," Life Sciences, vol. 90, no. 1-2, pp. 54-65, 2012. 

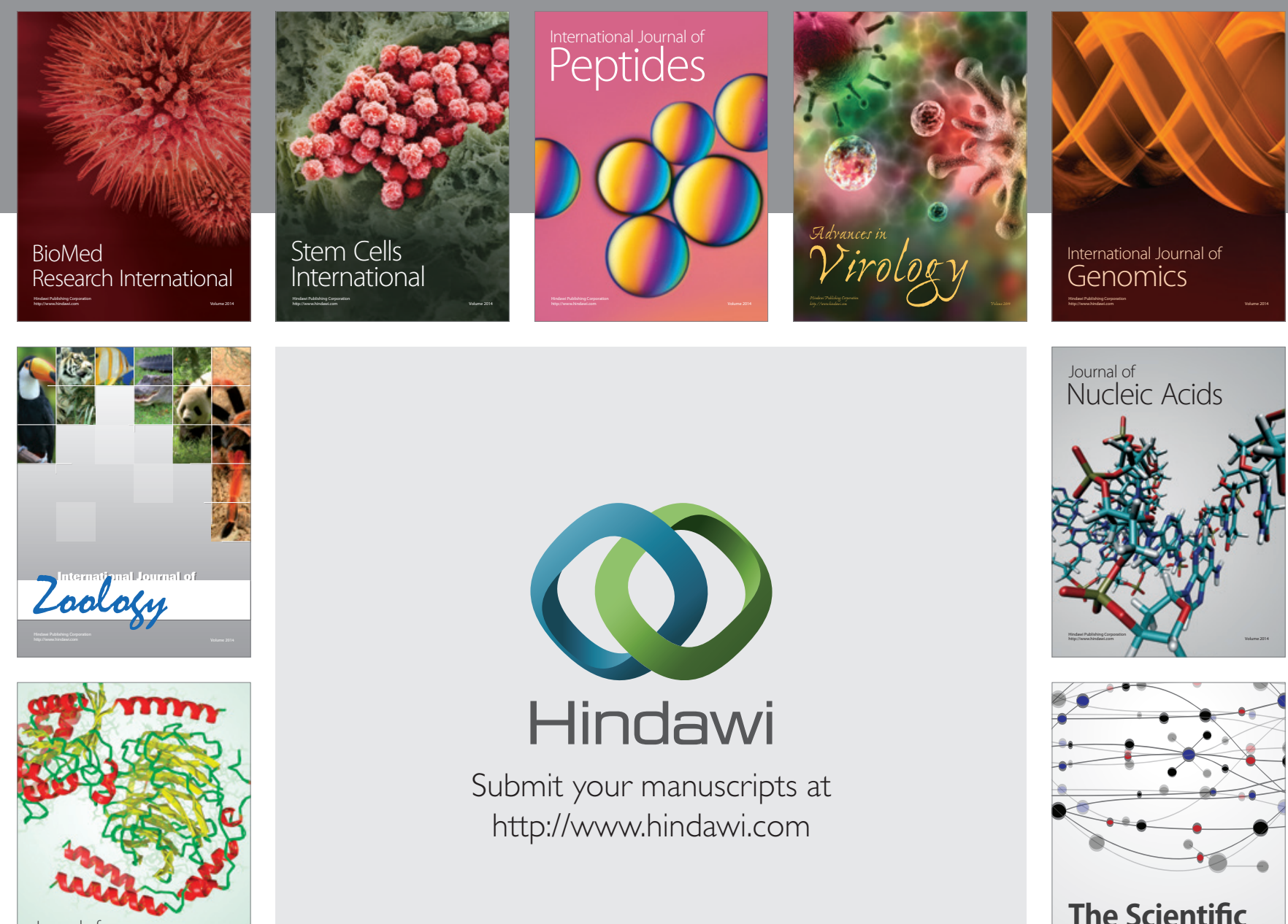

Submit your manuscripts at

http://www.hindawi.com

Journal of
Signal Transduction
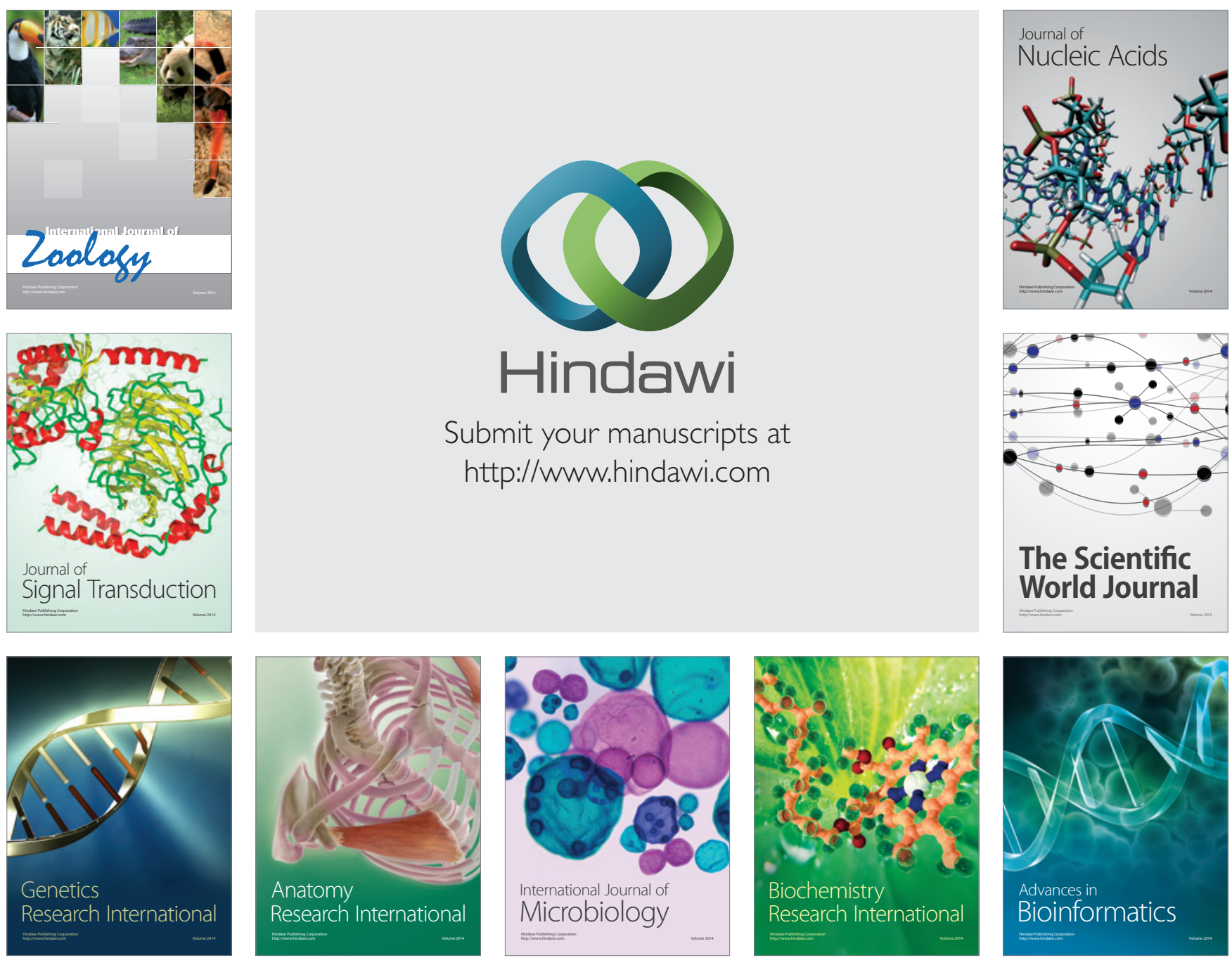

The Scientific World Journal
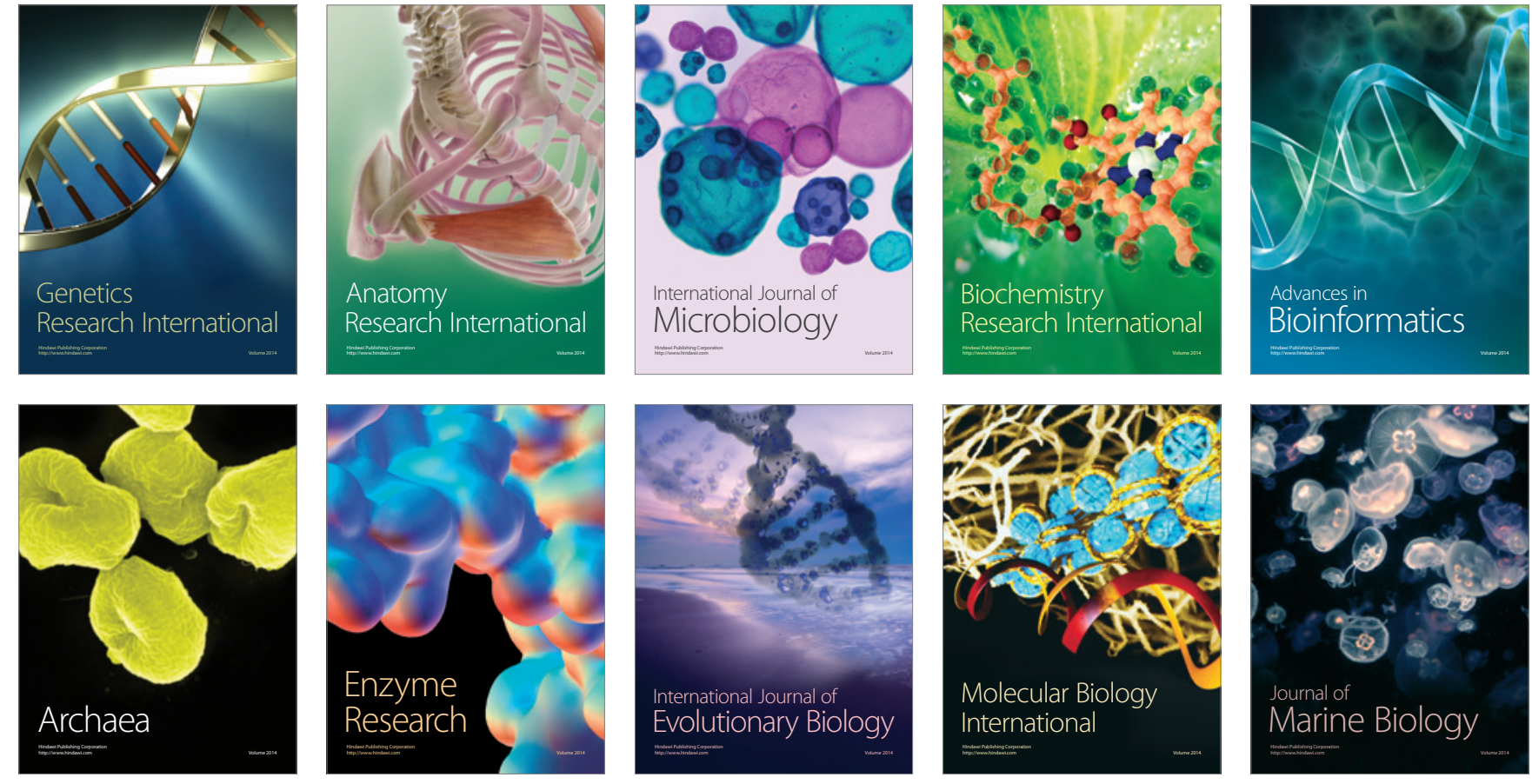